\title{
Bond Layer Properties and Geometry Effect on Interfacial Thermo- mechanical Stresses in Bi-material Electronic Packaging Assembly
}

\author{
D.Sujan, L. Vincent and Y. W.Pok \\ Faculty of Engineering and Science, Curtin University Malaysia \\ CDT 250, 98009 Miri, Sarawak, Malaysia
}

\begin{abstract}
Thermo-mechanical mismatch stress is one of the reasons for mechanical as well as functional failure between two or more connected devices. In electronic packaging, two or more plates or layers are bonded together by an extremely thin layer. This thin bonding layer works as an interfacial stress compliance which is expected to alleviate the interfacial stresses between the layers. Therefore, it is very important to identify the suitable interfacial bonding characteristics for reducing the interfacial thermal mismatch stresses to maintain the structural integrity. This research work examines the influences of bond layer properties and geometry on the interfacial shearing and peeling stresses in a bi-material assembly. In this study a closed form model of bi-layered assembly is used with the up-todate bond layer shear stress compliance expression. The key bond layer properties namely Young's modulus, coefficient of thermal expansion, Poisson's ratio, and physical parameters like temperature and thickness are considered for interfacial stress evaluation. It is observed that the Young's modulus, the thickness and the temperature of the bond layer have significant influence on the interfacial shearing and peeling stress. The results obtained are likely to be useful in designing bond layer properties in microelectronics and photonics applications.
\end{abstract}

\section{Introduction}

Interfacial thermal stresses are induced due to the mismatches of thermal, stiffness and other properties caused by the dissimilar materials. This mismatch of properties is often unavoidable due to the functional requirement of the materials in the package. Unfortunately this induced thermo-mechanical mismatch stress is one of the main causes of mechanical and functional failure in electronic and photonic devices. As the power requirement of the devices increases, the problem with thermal mismatch assumes a major cause of failure in electronic packages [1-8 ].

Nevertheless, in electronic packaging, two or more materials are bonded together by an extremely thin interfacial stress compliant attachment. This bond material can provide appreciable buffering effect which can lead to a substantial relief in thermally induced stresses in various adhesively bonded or soldered assemblies in electronics and photonics [8-9] Selection of bond material properties and thickness should also be addressed at the physical design stage for optimum mechanical performance of the device.

Three main approaches can analyze thermal stresses in layered structure namely 2-D elasticity solution, elementary beam theory and finite element (FE) analysis
[10]. However, beam theory is very popular among the researchers due to its simplicity. In beam theory, it considers a unit strip is cut parallel to the plane and then analyzes the stresses in that strip. The analysis is even more simplified by replacing the stresses on the crosssection by equivalent resultant forces and moments [1].

Suhir [11-12] studied the magnitude and distribution of stresses in adhesively bonded bi-material assemblies, with consideration of the attachment compliance. Compliance attachments, providing a strain buffer between thermally mismatched materials, can offer substantial stress relief, and for this reason, are considered in many cases as an acceptable solution to the thermal mismatch problem. Suhir showed that for relatively small assemblies, compliant attachment could indeed result in substantial stress relief in both the adherents and the adhesives.

Sujan proposed a model for shearing and peeling stresses at the interface of bi-material assembly which satisfies the interface compatibility by matching of strains at the interface rather than the actual displacements as in Suhir's work [1, 6, 13-15]. As a consequence, an unnecessary integro-differential equation was avoided by solving only a simpler second order differential equation.

Suhir [14] defined interfacial shear stress compliance for bond layer $\mathrm{K}_{0}$ as $2 \mathrm{t}_{0} / \mathrm{G}_{0}$, where $\mathrm{t}_{0}$ is the thickness and 
$\mathrm{G}_{0}$ is the shear modulus of rigidity of the bond material. Schmidt [5] used the relationship for $\mathrm{K}_{0}$ as $\mathrm{h}_{0} / \mathrm{G}_{0}$. However, Schmidt did not show any derivation for $\mathrm{K}_{0}$. Schmidt also carried out a numerical solution for a bimaterial assembly with bond layer where shear stress is compared for different $\mathrm{K}_{0}$ values i.e. $2 \mathrm{t}_{0} / 3 \mathrm{G}_{0}, \mathrm{t}_{0} / 3 \mathrm{G}_{0}$, and $\mathrm{t}_{0} / \mathrm{G}_{0}$. Sujan proposed shear stress compliance with complete derivation eliminated the contradiction of using different compliance expressions by earlier researchers $[4$, $6,15]$.

In this study a closed form model of bi-layered assembly is used with the up-to-date bond layer shear stress compliance expression [4]. The key bond layer properties namely Young's modulus, coefficient of thermal expansion, Poisson's ratio, and physical parameters like temperature and thickness are considered for interfacial stress evaluation.

\section{Analytical model}

The analytical model used in this project is developed using second order differential equation which does not involved any integro-differential equation. Figure 1(a) shows an arbitrary location of the model in 2dimensional form and Figure 1(b) shows the free body diagram of the full length of the model. The model is considered to be a unit of width in a direction perpendicular to the plane of the paper and the forces and moments are defined with respect to the unit width.

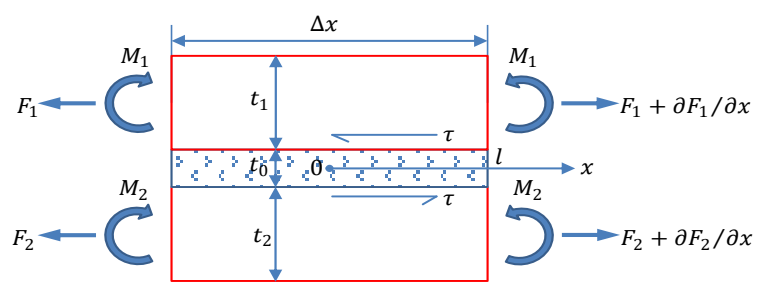

(a)

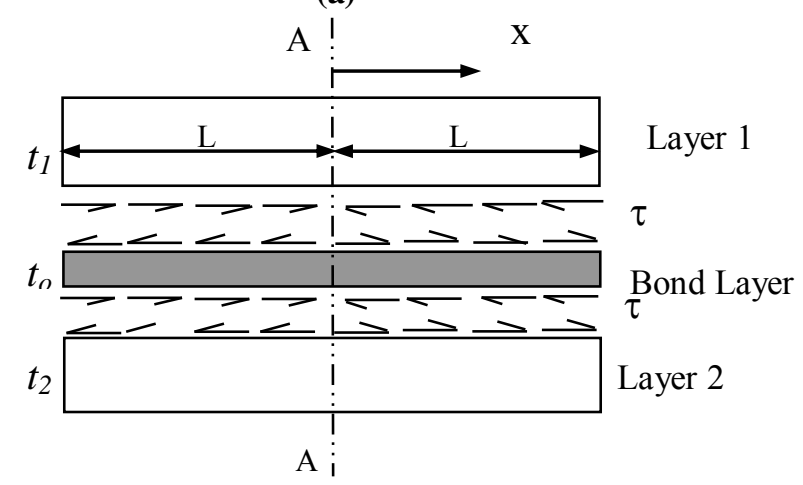

(b)

Figure 1. (a) Bi-material assembly and (b) free-body diagram of the model $[4,6,15]$

\section{Symbols used in this paper:}

Material or layer number, $i=1,2 ; \mathrm{E}=$ Young's modulus $\left(\mathrm{N} / \mathrm{m}^{2}\right) ; t_{\mathrm{i}}=$ Thickness $(\mathrm{m}) ; \Delta T=120^{\circ} \mathrm{C}$

$\alpha_{\mathrm{i}}=$ Coefficient of thermal Expansion $\left(1 /{ }^{\circ} \mathrm{C}\right)$;

$v_{i}=$ poison's ratio; $R=$ Radius of curvature; Shear modulus of rigidity, $G_{i}=\frac{E_{i}}{2\left(1+v_{i}\right)}\left(\mathrm{N} / \mathrm{m}^{2}\right)$; Flexural rigidity, $\mathrm{D}_{\mathrm{i}}=\frac{E_{i} t_{i}^{3}}{12\left(1-v_{i}^{2}\right)} \quad$ (kg.m); Effective flexural rigidity, $D=D_{1}+D_{2}$ (kg.m); Axial compliance, $\lambda_{i}=\frac{1}{E_{i} t_{i}}(\mathrm{~m} / \mathrm{kg})$; Shear compliance for top and bottom layer, $K_{i}=\frac{t_{i}}{3 G_{i}}\left(\mathrm{~m}^{3} / \mathrm{N}\right)$; Shear compliance for the bond layer, $K_{0}=\frac{t_{0}}{G_{0}}\left(\mathrm{~m}^{3} / \mathrm{N}\right)$

\section{The solution is based on the assumptions as follows:}

1. Thickness of the layered assembly is relatively small.

2. Each layer can be regarded as Bernoulli beam

3. Spherically bending thin plate is acted in each layer.

4. No external force acting among them.

5. Axial force due to thermal loading varies along the length and full shear length in the interface bonded layers.

6. Adhesive layer (solder bond) is very thin compared to the top and bottom layers

The shear stress $\tau(\mathrm{x})$ is given by,

$$
\tau=\frac{\Delta T\left(\alpha_{1}-\alpha_{2}\right)}{K \kappa \cosh (\kappa L)} \sinh (\kappa x)
$$

The peeling stress $\mathrm{P}(\mathrm{x})$ expression is given by,

$$
P=\frac{\left(t_{1} D_{2}-t_{2} D_{1}\right)}{2 D} \frac{\Delta T\left(\alpha_{1}-\alpha_{2}\right)}{K \cosh (\kappa L)} \cosh (\kappa x)
$$

Where $t=t_{1}+t_{2}+2 t_{0}, \lambda=\lambda_{1}+\lambda_{2}+\frac{t\left(t_{1}+t_{2}\right)}{4 D}$, and $K=K_{1}+K_{2}+K_{0}$ and $\kappa=\sqrt{\frac{\lambda}{K}}$ 


\section{Numerical example:}

An arbitrary bi-layered package system was used in this study. Table 1 shows the parameters used to calculate the interfacial stresses by using the analytical approach. The length of the assembly is $2 L=0.005 \mathrm{~m}$. The temperature changes, $\Delta T$ is taken at $120^{\circ} \mathrm{C}$ in this computation.

Table 1. Material properties and dimension

\begin{tabular}{|c|c|c|c|c|}
\hline Material & $\begin{array}{c}\text { Young's } \\
\text { Modulus, } E \\
(\mathrm{GPa})\end{array}$ & $\begin{array}{c}\text { CTE, } \alpha \\
\left({ }^{\circ} \mathrm{C}\right), \\
10^{-6}\end{array}$ & $\begin{array}{c}\text { Poisson's } \\
\text { Ratio, } v\end{array}$ & $\begin{array}{c}\text { Thickness } \\
t, \mathrm{~mm}\end{array}$ \\
\hline Die & 110 & 2.9 & 0.31 & 0.40 \\
\hline $\begin{array}{c}\text { Die } \\
\text { attach }\end{array}$ & 141 & 22 & 0.28 & 0.20 \\
\hline $\begin{array}{c}\text { Bond } \\
\text { layer }\end{array}$ & $10-70$ & $5-25$ & $0.25-0.33$ & $0.04-0.08$ \\
\hline
\end{tabular}

\section{Results and discussion}

The shearing stress and peeling stress are calculated using eq. (1) and eq. (2) respectively. The results are plotted in Figure 2 to Figure 5 and Table 3 to Table 4.The interfacial stresses are tabulated from $\mathrm{x} / \mathrm{L}=0.91-1.0$, since the stress values are significantly high in the vicinity of the edge. The maximum shearing stress and peeling stress are recorded at the free end $(x / L=1.0)$ as expected.

\subsection{Young's modulus (stiffness) effect}

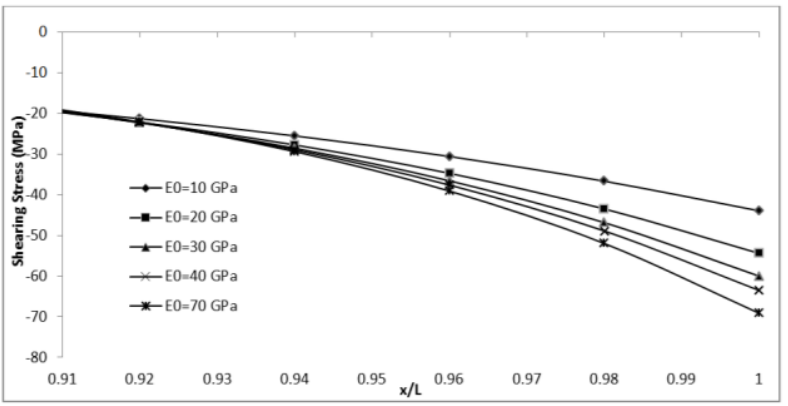

Figure 2. Shear Stress along the interface with Young's Modulus as parameter

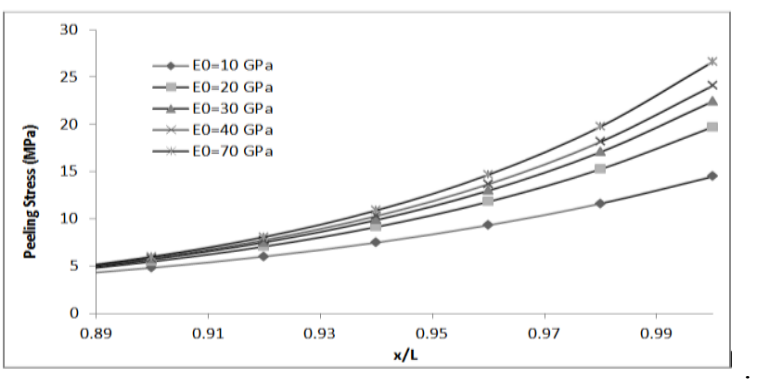

Figure 3. Peeling stresses along the interface with Young's Modulus as parameter
Figure 2 and Figure 3 represent shearing and peeling stresses for different values of Young modulus along the interface. The Young modulus of bond layer, $E_{0}$ is varied from 10 to $70 \mathrm{MPa}$ at the interval of $10,20,30,40$, and $70 \mathrm{MPa}$. From the Figure 2 and 3 above, it can be noticed that the shearing stress is tensile while peeling stress is compressive in nature along the interface as suggested in theory. It is observed that the shearing stress and peeling stress decreased due to the compliant (lower young's modulus) bond layer effect at any identical location at the interface. Particularly, near the vicinity of the free end, the differences of thermo-mechanical stress between highest modulus and lowest modulus of bond layer were significant, which is $76.1 \%$ for shearing stress and $84.5 \%$ for peeling stress. Thus, it indicates that a more compliant bond will likely to result in smaller interfacial stress compared to a stiffer bond. At this point, it is worth mentioning here that a compliant bond is likely to generate smaller interfacial stress but it is easier to deform. On the other hand, a stiffer bond is likely to results in higher stresses but it is more difficult to deform [3].

\subsection{Thickness effect}

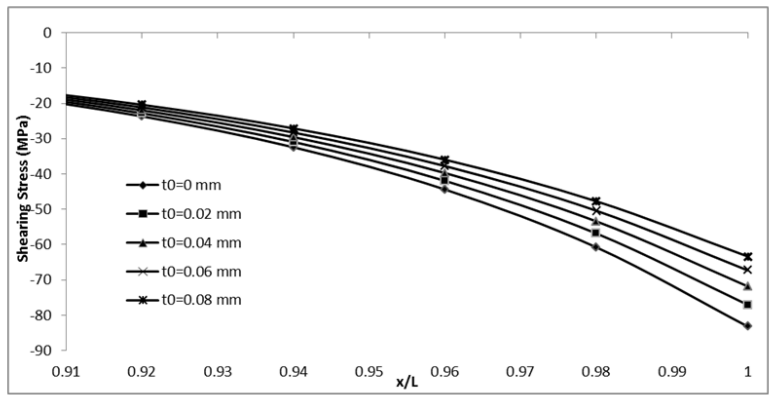

Figure 4. Shear stresses along the interface of different bond layer thickness.

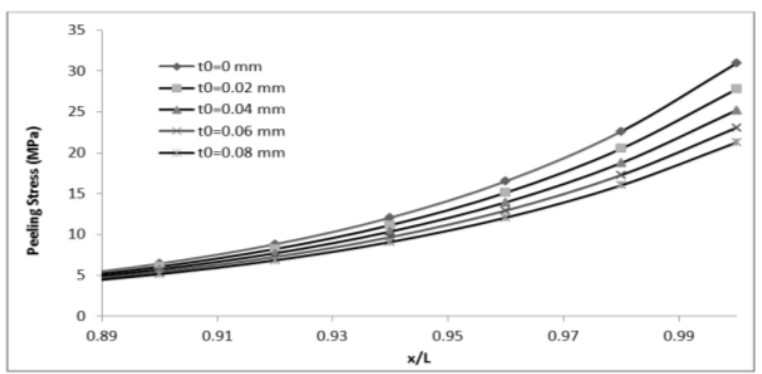

Figure 5. Peeling stresses along the interface of different bond layer thickness.

Figure 4 and Figure 5 compared shearing stress and peeling stress respectively with bond layer thickness, $h_{0}$ as a parameter. The results are plotted only from $x / L=$ 0.91 to 1 to represent significant effects of bond layer thickness near the vicinity of the free end.

It is evident from Figure 4 and Figure 5 that shearing and peeling stresses decreased with the increase of compliant bond layer thickness at any identical location along the interface. For instance, at location $\mathrm{x} / \mathrm{L}=1$, the 
shearing stress recorded as 157.9 MPa, 120.8 MPa, 109.5 $\mathrm{MPa}, 100.4 \mathrm{MPa}$, and $93.06 \mathrm{MPa}$ with bond layer thicknesses of $\mathrm{h}_{0}=0 \mathrm{~mm}, 0.02 \mathrm{~mm}, 0.04 \mathrm{~mm}, 0.06 \mathrm{~mm}$, and $0.08 \mathrm{~mm}$ respectively. Similar trend of variation is also observed in Figure 5 for the case of peeling stresses.

For both interfacial stresses distribution, the shear stress and peeling stress were observed to be reduced along the length when the thickness of bond layer was being increased. The increased bond layer thickness would generated a surrogate layer acted for shear stress absorption along the interface.

Therefore, a higher value of bond layer thickness would be suggested in the flip-chip packaging design. However, the increased bond thickness was seem to be another concern for the increased overall cost of material.

\subsection{Poisson's ratio effect}

Table 2. Stresses at location $\mathrm{x} / \mathrm{L}=1$ for different Poisson's ratio

\begin{tabular}{|c|c|c|c|c|c|}
\hline $\begin{array}{c}\text { Poisson's } \\
\text { Ratio, } v\end{array}$ & $\mathbf{0 . 2 5}$ & $\mathbf{0 . 2 7}$ & $\mathbf{0 . 2 9}$ & $\mathbf{0 . 3 1}$ & $\mathbf{0 . 3 3}$ \\
\hline $\begin{array}{c}\text { Shear Stress } \\
(\mathrm{MPa})\end{array}$ & -43.9 & -43.7 & -43.5 & -43.2 & -43.0 \\
\hline $\begin{array}{c}\text { Peeling Stress } \\
(\mathrm{MPa})\end{array}$ & 29.9 & 29.8 & 29.7 & 29.6 & 29.5 \\
\hline
\end{tabular}

Table 2 represents the shear and peeling stress values at location $\mathrm{x} / \mathrm{L}=1$ (edge) with Poisson's Ratio varied in the range of $0.25-0.33$. It can be observed that the both shear and peeling stress changes very slightly due to the variation of Poisson's Ratio. Thus, Poisson ratio of bond layer do not play significant role in reducing interfacial stresses in layered structure. From the above observation it can be concluded that the effect of Poisson ratio in bond layer may not be essential to consider in predicting stresses development at the interface.

\subsection{Thermal expansion coefficient effect}

From eq. (1) and Eq. (2), it can be observed that the coefficient of thermal expansion of bond layer term is absent or has no effect in shearing and peeling stress expressions for with bond layer consideration. This is due to the fact that the bond layer is extremely thin compared to the two adhere layers. Therefore, it does not contribute much in terms of expansion and compression of the overall package. Therefore, it can be concluded that the coefficient of thermal expansion of the bond layer insignificant contribution in predicting stresses development at the interface.

\subsection{Temperature Effect}

Table 3. Stresses at location $\mathrm{x} / \mathrm{L}=1$ for different temperature

\begin{tabular}{|c|c|c|c|c|c|}
\hline $\begin{array}{c}\text { Temperature, } \\
{ }^{\circ} \mathrm{C}\end{array}$ & $\mathbf{6 0}$ & $\mathbf{8 0}$ & $\mathbf{1 0 0}$ & $\mathbf{1 2 0}$ & $\mathbf{1 4 0}$ \\
\hline $\begin{array}{c}\text { Shear Stress } \\
(\mathrm{MPa})\end{array}$ & -31.7 & -42.3 & -52.9 & -63.5 & -74.1 \\
\hline $\begin{array}{c}\text { Peeling Stress } \\
(\mathrm{MPa})\end{array}$ & 17.4 & 23.2 & 29.0 & 34.8 & 40.6 \\
\hline
\end{tabular}

From eq. (1) and eq. (2), it can be observed that the bond layer term is also absent in shearing and peeling stress expressions for with bond layer consideration. This is due to the fact that the bond layer is extremely thin compared to the two adhere layers. Therefore, it can be logically assumed that the bond layer temperature will be same as the overall package. Nevertheless, Table 3 clearly indicates that the temperature is a very significant factor in stress development in the interface. For instance, shear stress increases $233 \%$ for an increment of temperature from $60^{\circ} \mathrm{C}$ to $120^{\circ} \mathrm{C}$ at the edge of the package. Therefore, it can be concluded that the temperature should be as low as possible during manufacturing and operation of electronic packages to avoid mechanical and functional failure.

\section{Conclusions}

This research work examined the influences of bond layer properties and geometry on the interfacial shearing and peeling stresses in a bi-material assembly. In this study a closed form model of bi-layered assembly was used with the up-to-date bond layer shear stress compliance expression. The key bond layer properties namely Young's modulus, coefficient of thermal expansion, Poisson's ratio, and physical parameters like temperature and thickness were considered for interfacial stress evaluation. It is observed that the Young's modulus, the thickness and the temperature of the bond layer have significant influence on the interfacial shearing and peeling stress. The shearing stresses and peeling stresses decreased considerably at the interface with the increase of bond layer Young Modulus and thickness. On the other hand, Bond layer coefficient of thermal expansion and Poisson ratio show almost no significant effect on the interfacial shearing stress and peeling stress along the interface in a bi-material assembly. The results obtained are likely to be useful in designing bond layer properties in microelectronics and photonics applications.

\section{Acknowledgement}

The authors thankfully acknowledge the research facilities and infrastructure provided by the Curtin University Malaysia and the financial assistance provided by the Ministry of Higher education (Malaysia) under FRGS scheme, Grant reference Code: FRGS/2/2013/SG06/CURTIN/02/1

\section{References}

1. Timoshenko. S. (1925). Analysis of Bi-Metal Thermostats. Journal of the Optical Society of America.11, pp. 233-255

2. Tummala, R. (2001). Fundamentals of microsystems packaging. McGraw Hill Professional.

3. Moore, G. E. (1998). Cramming more components onto integrated circuits. Proceedings of the IEEE, 86(1), 82-85. doi:10.1109/JPROC.1998.658762

4. Sujan, D., Woldemichael, D. E., Murthy, M. V. V., \& Seetharamu, K. N. (2011). Effect of bond layer on 
bimaterial assembly subjected to uniform temperature change. Journal of Electronic Packaging, Transactions of the ASME, 133(4) doi:10.1115/1.4005294

5. Brown, W. D. (1998). Advanced Electronic Packaging with Emphasis on Multichip Modules. ed.

6. Sujan, D., Pang, X. B., Rahman, M. E., \& Reddy, M. M. (2014). Performance of solder bond on thermal mismatch stresses in electronic packaging assembly doi:10.4028/www.scientific.net/MSF.773-774.242

7. Huang, Y.W., Lin, Y. M., Zhan. C.J. (2013). Assembly of 3D Chip Stack with $30 \mu \mathrm{m}$-Pitch Micro Interconnects Using Novel Arrayed-Particles Anisotropic Conductive Film. Proceedings of the 2013 Electronic Components and Technology Conference, pp. 71-76.

8. Suhir, E. (2018). Analytical thermal stress model for a typical flip-chip (FC) package design. Journal of Materials Science: Materials in Electronics, 29(4), 2676-2688. doi:10.1007/s10854-017-8194-6

9. Suhir, E. (2014). Thermal stress in through-siliconvias: Theory-of-elasticity approach. Microelectronics Reliability, 54(5), 972-977. doi:10.1016/j.microrel. 2014.01.004

10. Gao, L., Chen, X., \& Gao, H. (2015). Interfacial thermal stresses in ACF bonding assembly. Microelectronics Reliability, 55(7), 1089-1096. doi:10.1016/j.microrel.2015.04.004
11. Suhir, E. (1989). Interfacial stresses in bimetal thermostats. Journal of Applied Mechanics, Transactions ASME, 56(3), 595-600. doi:10.1115/1.3176133

12. Suhir, E. (1986). CALCULATED THERMALLY INDUCED STRESSES IN ADHESIVELY BONDED AND SOLDERED ASSEMBLIES. Paper presented at the 383-392.

13. Sujan, D., Murthy, M. V. V., Seetharamu, K. N., \& Hassan, A. Y. (2005). Complete model for interfacial stresses of a two layered structure. Paper presented at the Proceedings of the 6th International Conference on Thermal, Mechanical and Multi-Physics Simulation and Experiments in Micro-Electronics and Micro-Systems - EuroSimE 2005, , 2005 454461. doi:10.1109/ESIME.2005.1502848

14. Sujan, D., Murthy, M. V. V., \& Seetharamu, K. N. (2011). Improved tri-layered interfacial stress model with the effect of different temperatures in the layers. Archive of Applied Mechanics, 81(5), 561-568. doi:10.1007/s00419-010-0437-4

15. Sujan, D., Murthy, M. V. V., Seetharamu, K. N., \& Hassan, A. Y. (2005). Engineering model for interfacial stresses of a heated bimaterial structure with bond material used in electronic packages. Journal of Microelectronics and Electronic Packaging, 2(2), 132-141. doi:10.4071/1551-48972.2.132 